\title{
Lesson Planning in Primary School Using Lesson Study and Open Approach
}

\author{
Alisa Moonsri ${ }^{1}$, Auijit Pattanajak ${ }^{2}$ \\ ${ }^{1}$ Faculty of Education, Khon Kaen University, Khonkaen, Thailand \\ ${ }^{2}$ Center for Research in Mathematics Education, Faculty of Education, \\ Khon Kaen University, Khonkaen, Thailand \\ Email: koyAliss@hotmail.com
}

Received September 25 ${ }^{\text {th }}$,2013; revised October 23 $3^{\text {rd }}, 2013$; accepted November $21^{\text {st }}, 2013$

\begin{abstract}
Copyright $\odot 2013$ Alisa Moonsri, Auijit Pattanajak. This is an open access article distributed under the Creative Commons Attribution License, which permits unrestricted use, distribution, and reproduction in any medium, provided the original work is properly cited. In accordance of the Creative Commons Attribution License all Copyrights (C) 2013 are reserved for SCIRP and the owner of the intellectual property Alisa Moonsri, Auijit Pattanajak. All Copyright $@ 2013$ are guarded by law and by SCIRP as a guardian.
\end{abstract}

Lesson plans are generally written in a way that helps teachers to layout and run classroom activities. Many researchers have examined how teachers go about planning. This clearly shows that instructional plans play a central role in teaching and creating effective learning environments (Clark \& Dunn, 1991; Reiser \& Dick, 1996; Shauelson, 1983 cited in Koszalka et al., 1999). In context of school using lesson study and open approach followed conception of Inprasitha (2010), the importance of lesson study processes is collaborative lesson planning. After that the teachers who participate in lesson study group use these lesson plans in the classroom, observe and collect students' thought and learning processes. And in planning the lessons use problems that students encounter in everyday life, so as to stimulate students to work to achieve the objective (Fernandez \& Yoshida, 2004). The data were collected by video and audio recording while the target group were planning and teaching the lessons in lesson study process, then were transcribed to the protocol and analyzed by using theoretical framework of Stigler and Hiebert (1999). The research revealed that the target group discussed during the lesson planning process detailing about exact words, problem situations, materials, the anticipated solutions, students' thoughts and responses, time used in each part of the lesson, and how to summarize the lesson. In the lesson planning, the exact words used in the problem situations were mostly mentioned. Moreover, in lesson planning, the issue of details of introduction design was discussed a lot. There were some issues which were not discussed during the teachers-included designing of the lesson plan. However, they were discussed while the teacher was using the lesson plan in class during instructional management.

Keywords: Planning the Lesson; Lesson Study; Open Approach

\section{Introduction}

Lesson study is a professional learning process that Japanese teachers engage in continuously throughout their careers to examine systematically their instructional methods, teaching content and curriculum as well as their students' processes of learning and understanding in order to achieve their educational goals (Yoshida, 2008) and it exemplifies qualities of effective professional learning (Lewis, 2011). The theory of mathematics education which has been developed with teachers through lesson study and shared by teachers in daily teaching practices can support better reproduction of the mathematics class in order to develop children's mathematical thinking (Isoda \& Katagiri, 2012). There are important benefits of the collaborative nature of lesson study that provide a benchmarking process that teachers can use to gauge their own skills. Collaboration includes continuing interactions about effective teaching methods plus observations of one another's classrooms (Stigler \& Hiebert, 1999). One adaptation is to incorporate open approach as a teaching approach into lesson study processes. The adaptation of lesson study and open approach into schools, we have seen the major change in the classroom in response to the educational reform. Introducing lesson study into Thai schools has much influence not only on improving teaching practice in schools, but also for improving the system of teacher education as a whole.

Lesson planning was a major task of teachers. Teaching would be successful or not, and how much, was based on the planning. If teachers had good teaching plan, it was like half done. According to National Education Act 1999, Section 4: the guidelines for educational management in every standard focused on student-centered; if the students' opinions and needs were collected as guidelines for writing, it would be better. It was based on assumption that each teacher had collected experience and expertise, or skill. So, they should be provided with opportunity in expressing their potentiality, determining the activity for their own learning fully (National Education Act, 2002).

Lesson plan written in general, was model and guideline for teachers as well as for implementing classroom activity. Many researchers surveyed teachers' teaching planning techniques, it 
was clearly indicated that the lesson plans play a major role in teaching as well as constructing the efficient learning environment (Clark \& Dunn, 1991; Reiser \& Dick, 1996; Shauelson, 1983 cited in Koszalka et al., 1999). The teachers’ preparation in lesson plan is an important thing for determining teaching goal, considering the existing resources, and designs the activity appropriately (Lee \& Yakahashi, 2011). Fernandez and Yoshida (2004) stated that for lesson planning, basic problems of students found in daily life were used as stimulators for students to achieve goal. Moreover, it could change and support the students to learn that lesson as well as plan for searching for in order to find an appropriate approach through the students' processes. Moreover, the students hope to solve different problems. Therefore, the basic problems in daily life would help them to accomplish the lesson objective.

In present situation, teachers still have bad attitude towards lesson planning. Although they have approved that the lesson plan is useful as developmental plan of every teacher's instructional management quality which was the responsibility of each teacher. Each of them has accusation that one had to teach many subjects, many periods, also be responsible in other kinds of work. Another major cause of them to feel bored with lesson planning is the process enhancing the establishment of lesson planning which is not based on principles of sufficiency, appropriateness, and unsystematic and hierarchical development (Kamkerd, 2004).

The most frequently used one of lesson plans using in general class is the class with teacher-centered leader of learning. The students receive knowledge from the teachers. The teachers are knowledgeable in many aspects, and use the knowledge feeding technique for students by lecturing and explaining for the students throughout the time. They perform activities themselves without providing opportunity for students to pick up or touch the instructional media shown by teachers. The students do not have a chance to speak, or work in group to search for answer. Most of them use media included chalk and blackboard. In contrast, in the lesson study innovation classes are the classes facilitating the new instructional management which cause the students to have freedom to learn either in group or individual with the teachers as their consultants. In this kind of classroom management, teacher is the monitor and advisor for the students and the students play their role and learn from media. Therefore, this kind of classroom management was congruent with curriculum objective which wants the students to search for, analyze and critique, and practice every step until they could lean by themselves (Rattanasomboon et al., 2010).

\section{Research Methodology}

This research was a qualitative research. Data were presented by descriptive analysis in context of schools under the project of Mathematics Teaching Professional Development through the Lesson Study and Open Approach. The Lesson Study was implemented based on Inprasitha's (2010) including 3 phases of implementation including phase 1) Collaboratively design research lesson, phase 2) Collaboratively observing the research lesson, and phase 3) Collaboratively reflection on teaching practice. The first phase is the phase that the teacher and internship students in school collaborate in planning the lesson together, would be emphasized.

\section{1) Target Group}

This study was the study in lesson planning of the Lesson
Study group participating in the project of Lesson Study and Open Approach for 6 years, as the schools using Lesson Study continuously, using data collection by participatory observation in lesson planning step which was depend on the type of lesson planning.

The target group of this study, consisted of the in-service teacher with responsibility in teaching, teacher observer in mathematics subject of grade 1 , the internship student in mathematics education with responsibility as teacher and teacher observer in mathematics subject of grade 1 , the researcher or research assistant from Center for Research in Mathematics Education, Faculty of Education, Bung-neum-bung-krai-nun School, Muang District, Khonkaen Province, a school under the Project of Teaching Professional Development based on Lesson Study using learning management through Lesson Study and Open Approach.

\section{2) Research Instruments}

In conducting this research, the researcher used 2 kinds of Instruments: the instrument using for data collection, and the instrument using for data analysis, as follows:

a) The Activity Record Form in collaborative establishment of knowledge management plan was constructed by Center for Research in Mathematics Education, as an instrument using for collecting data during knowledge management planning (Mathematics Education, Faculty of Education) in 4 major issues.

b) The Field Note, used by taking note of spoken words and opinion expression during the phase of collaborative establishment in teaching observation, and reflection.

c) The audio-tape recorder was an instrument for recording sound during the phase of collaborative observation and reflection.

d) The video-tape recorder, used for recording collaborative lesson planning from the beginning of planning

\section{3) Data Analysis}

Qualitative data analysis was administered in this study. The researcher used protocol data from the step of collaborative establishment of lesson, collaborative observation, and collaborative reflection obtaining from deciphering audio tape and video tape recorder, field note, activity record form from collaborative establishment of learning organization plan, and students' performance in order to have complete and clear information to be analyzed. Data were analyzed based on framework of lesson planning of Stigler and Hiebert (1999), and presented in descriptive analysis.

\section{Results}

In school context using Lesson Study and Open Approach, lesson planning was a guideline helping teachers, and a model in implementing classroom activity. Inprasitha (2010) stated that the major process of Lesson Study was the collaborative planning for teaching in group. Then, the teacher in Lesson Study group used the lesson plan in classroom context of school using Lesson Study and Open Approach based on Inprasitha's (2010) approach including 3 phases of implementation: Phase 1; Collaboratively design research lesson, Phase: Collaboratively observing the research lesson, and Phase 3; Collaboratively reflection on teaching practice. The researcher presented research findings based on Stigler and Hiebert (1999) approach as follows:

Lesson planning in schools using lesson study and open ap- 
proach

There are important benefits of the collaborative nature of lesson study are that provides a benchmarking process that teachers can use to gauge their own skill. Collaboration includes continuing interactions about effective teaching methods plus observations of one another's classrooms (Stigler \& Hiebert, 1999). One adaptive is to incorporate as a teaching approach into lesson study processes.

In the phase of collaboratively design research lesson, the Lesson Study Group collaborated in planning the lesson together. There were 6 issues being discussed during planning as follows:

Issue 1: The problem with which the lesson would begin in class.

"the little detectives in each group out ping-pong ball into wonderful box, then, record the code number in recording card without repetition,"

Item 6: If I bring the nearby, I'm afraid of getting similar activity. Firstly, separating 5 further. If I separate 6, I'm afraid the students would remember the answer. The first period is to separate 5 number. We have this kind of box for one box. Our goal is: we want the students to know that 5 , what is structure of 5 . It consisted of 1 with 2 , with 3 , with 4 , with 5 , with 0 . Separate 5 into 2 numbers. We tried not to emphasize students to remember, isn't it? It seems that when the students see 5, they see 2 things. It might be 1,4 or 2, 3. The students should know that 5 could come from what. Is it the same box as the last year?

Item 7: Yes, the last year, one side was closed; ping-pong was shown in another side. They showed how many ping-pong balls in this side, it was closed this side. If there are 5, the teacher would tell that Oh! Today we have 5 ping-pong balls. Let you see in the box that I dropped it. If this side included 2 balls, how many balls are in the other side?

Item 72: Would we give an order to them? Think. Children couldn't read.

Item 73: Students couldn't read. This is what I wrote the order using in this activity for each of little detective, drop in on the board, then put it by themselves, and write it themselves (Protocol of lesson planning in Lesson Study Group).

It was discussed during lesson planning of the lesson study group: the problem at the beginning of lesson had to be consisted of details of introduction, the problem with the lesson would begin, including such details as the exact wording as a major issue discussed by the lesson study group.

Issue 2: Materials to solve the problem Construction or designing to be associated with introduction in the open-ended problem situation, with major media using for constructing the open-ended problem situation, and supplementary media using while the student were presenting their approach to the class, or while the teacher was concluding the lesson. Major media: wonderful box ping-pong ball Record Card Supplementary media presented paper magic pen.

Item 6: If I bring the nearby, I'm afraid of getting similar activity. Firstly, separating 5 further. If I separate 6, I'm afraid the students would remember the answer. The first period is to separate 5 number. We have this kind of box for one box. Our goal is: we want the students to know that 5 , what is structure of 5 . It consisted of 1 with 2 , with 3 , with 4 , with 5 , with 0 . Separate 5 into 2 numbers. We tried not to emphasize students to remember, isn't it? It seems that when the students see 5, they see 2 things. It might be 1,4 or 2, 3. The students should

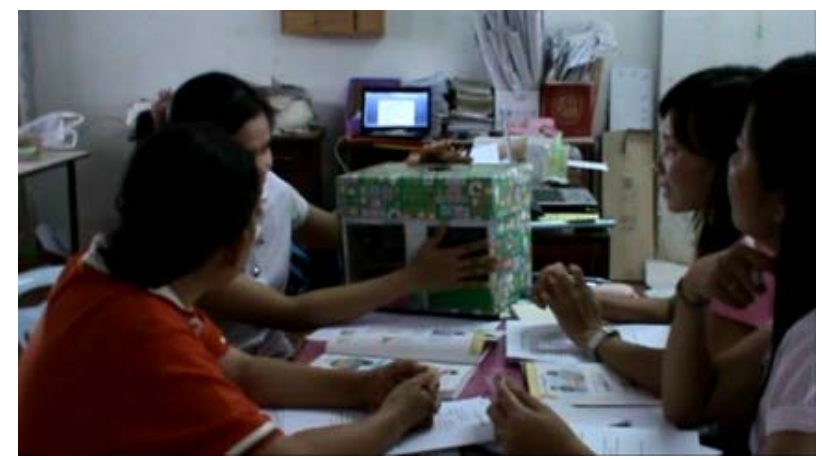

Figure 1.

Lesson planning in how many and how many (1).

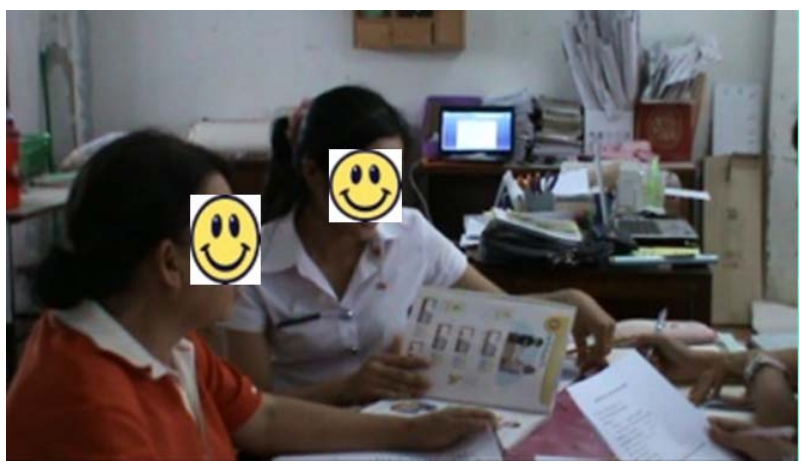

Figure 2.

Lesson planning in how many and how many (2).

know that 5 could come from what. Is it the same box as the last year?

Item 7: Yes, the last year, one side was closed; ping-pong was shown in another side. They showed how many ping-pong balls in this side, it was closed this side. If there are 5, the teacher would tell that Oh! Today we have 5 ping-pong balls. Let you see in the box that I drop it. If this side included 2 balls, how many balls are in the other side?

Item 8: But, this year I would take this in period 3 of number 7. Close this side and put 3 , and guess that how much this side, in the first period, should know that it could be separated into 2 .

Item 9: Yes. It showed that Nan wants to be clearly seen, isn't it? Both of 2 sides when we drop it, it is 5 sides. It is 2 sides. This is 2 sides. If it is 0 , this side would be 5 .

Item 10: order the Students to write on record paper that: what could 5 be separated into? There are techniques altogethers. But, the number of record card, teacher! The cards we want to distribute the students, this one would write 5, aren't it? This one would be omitted for children to fill it. I think that how many papers we should distribute to children first since all techniques.

Item 33: The issue said once by Nan in former time, close it first. If the box isn't closed, what it would be? (Protocol of lesson planning in Lesson Study Group).

The topic discussed in lesson planning of Lesson Study Group, was the materials students would be give to use in trying to solve the problem.

Issue 3: conjecture the students' techniques for problem solving (Lesson plan in how many and how many).

What could Number 5 be separated into?

Item 15: there are 4 groups. We should assign children to do 

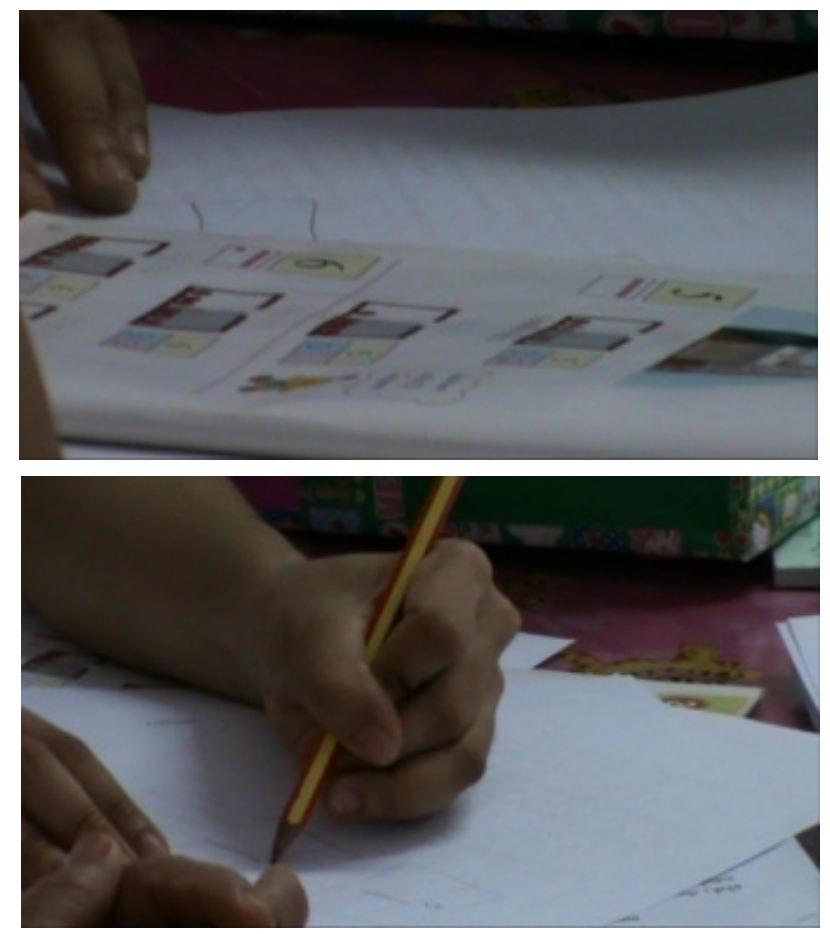

Figure 3.

Lesson planning in how many and how many (3).

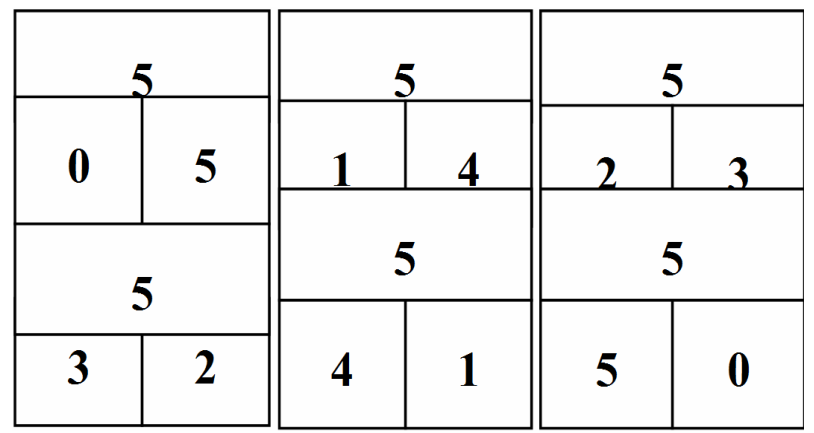

Figure 4.

conjecture the students' techniques for problem solving.

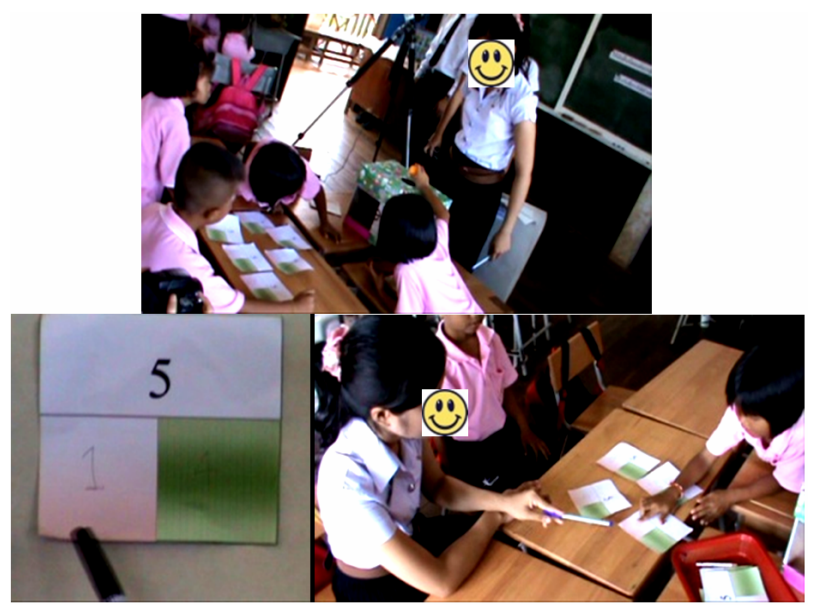

Figure 5.

Classroom activities. this. It comes from 0 and 5. But, if we do not give the children, If some children get 4 and 1 . Is it the same as 5 and 0 ?

(Protocol of lesson planning in Lesson Study Group)

It was discussed in lesson panning of lesson study group, was to conjecture the students' techniques for problem solving, thinking, and response in trying to construct new problem solving.

Issue 4: The kinds of questions could be asked to promote student in classroom.

Teacher and students collaborated in discussion about number structure of 5 . Teacher tried to ask question to stimulate the student that "What could 5 be separated into?" How many techniques are there from separation? And "Number 5".

From the introduction step, teacher, I would like to ask teacher that I tried to find situation in associating with this box. I don't know what to be associated with. I think of the safe. I want to ask you that if I ask my students, do you think my students would know or not” Do you ever see or know the sake? What the safe is used for?"

The issue was discussed during lesson planning of Lesson Study Group, was the kinds of question that could be asks to enhance and support the students' thinking during this lesson, to promote students' thinking during the lesson and the type of suggestions or recommendations which might be provided to the students who expressed one thing indicating misconception, or example of students' misconception.

Issue 5: How to apportion the fixed time of lesson

Introduction: Presentation of open-ended problem situation. (10 minutes).

1) Teacher greets students and speaks to them that "Do you know the safe?" What is the safe? What it is used for? Then, teacher told students that she has a safe, inside includes important thing in it. Yesterday, she wanted to bring that important thing out. But, she forgets its code. So, she supposes the students are little detectives with responsibility to search for the safe code she had lost. Are you ready to be little detectives? Then, she supposed the students be little detectives.

2) Teacher tells her students that she would assign little detectives into small group. Each group would have equipment to help them in searching for safe code. She showed the equipment to students, and asks them that "What do you see? Let you guess what the teacher wants them to do.

3) Teacher tells students that "today I want you to drop ping-pong ball. When they dropped the ball, little detectives record number of the balls in record card. Then, she informs how to record number of the balls in record card.

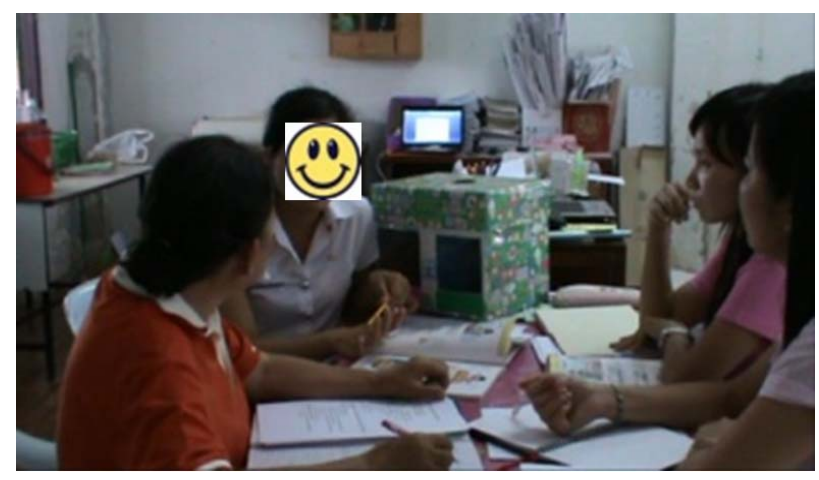

Figure 6.

Lesson planning in how many and how many (4). 
4) Teacher asks a volunteer student to drop the ping-pong ball. After dropping, she demonstrates how to record number of the balls in record card.

Teaching step: students learn by themselves for 20 minutes.

5) Teacher assigns students' group activity, introduction in the card is: "Let little detectives drop ping-pong balls into wonderful box. Then, record the code number in record card without repeating. Whole Class Discussion and Comparison for 25 minutes.

6) Teacher lets students to present in front of the class.

7) Teacher and students discuss the structure of number 5. She tries to ask questions to stimulate students that "What number could 5 be separated into?" How many techniques to separate it? Number 5 . Conclusion of lesson from association students' thinking occurs in class during 35 minutes.

8) Teacher and students conclude what they have learnt from activity and discuss in the class. Separating number 5 into 2 different numbers, the sum of those 2 numbers is 5 , total techniques in separating 5 .

(Lesson plan in how many and how many).

It was discussed in lesson planning of the lesson study group, was to fixed time of the lesson to be consistent and appropriate with different parts of lesson.

Issue 6: How to end the lesson

Teacher and students conclude what they have learnt from activity and discuss in the class. Separating number 5 into 2 different numbers, the sum of those 2 numbers is 5 , total techniques in separating 5 .

(Lesson plan in how many and how many).

Item 88: Now, from conclusion, the children could see that let them conclude by themselves. Children could see that: the 2 subparts were less than majority.

Item 89: If we let children speak out, it would be motivated question for them very much. We have to think that what kind of question to be occurred. It is based on the teacher's question. If children speak out, I think that the children could not.

Item 90: Children do not speak. Questions need to be used.

Item 91: Most of conclusion techniques: "What do we learn today? They would tell that 5 . Some of them might separate. Separate number 5.

(Protocol of lesson planning in Lesson Study Group).

It was discussed in lesson planning of Lesson Study group; the lesson conclusion was an important session for the students to comprehend the lesson very much.

\section{Summary and Prospective}

The planning of lesson in schools uses the Lesson Study and Open Approach based on framework of Stigler and Hiebert (1999). The researcher discussed the research findings as follows:

In lesson planning of target group, the discussed issue during lesson planning was the problem at the beginning of lesson included details of introduction, material and equipment and media which the students would receive for problem solving, conjecturing for problem solving, thinking approach, and students' response as trying to construct new problem, type of answer which might be asked for enhancing and supporting the students' ideas during lesson, technique for organizing time in class to be consistent and appropriate with different parts of the lesson. Technique for concluding the lesson was an important duration which they would be able to understand the lesson very much. In lesson planning, the issue of details of introduction design was discussed a lot. There were some issues which were not discussed during the teachers-included designing of the lesson plan. However, they were discussed while the teacher was using the lesson plan in class during instructional management.

In school context using the Lesson Study and Open Approach based on Inprasitha's (2010) approach, in order to see issues in planning for each lesson to be clear in lesson planning, each plan should be performed in each session. Many plans should not be performed in each time so that the discussed issues of lesson study group should be obviously seen. These obtained issues could be used as discussion guidelines during lesson planning for school starting to use the lesson study and open approach.

\section{Acknowledgements}

Research Promotion and National Research University Project of Thailand, Office of the Higher Education Commission, through the Cluster of Research to Enhance the Quality of Basic Education, Faculty of Education, Khon Kaen University. This work was supported by the Higher Education.

\section{REFERENCES}

Fernandez, C., \& Yoshida, M. (2004). Lesson study. London: Lawrence Erlbaum Associates.

Inprasitha, M. (2010). One feature of adaptive lesson study in Thailand: Designing learning unit. In Proceeding of the $45^{\text {th }}$ Korean National Meeting of Mathematics Education Dongkook University (pp. 193204). Gyeongju: Dongkook University.

Isoda, M., Stephens, M., Ohara, Y., \& Miyakawa, T. (2007). Japanese lesson study in mathematics. Singapore: World Scientific.

Isoda, M., \& Katagiri, S. (2012). Mathematical thinking: How to develop it in the classroom. Toh Tuck Link: World Scientific. http://dx.doi.org/10.1142/8163

Koszalka, T., Breman, J., \& Moore, M. K. (1999). Sharing lesson plans over the World Wide Web: Important components. Education and Information Technologies, 4, 143-151. http://dx.doi.org/10.1023/A:1009647900657

Lee, Y. A., \& Takahashi, A. (2011). Lesson plans and the contingency of classroom interactions. Human Studies, 34, 209-227. http://dx.doi.org/10.1007/s10746-011-9181-1

Lewis, C. (2002). Lesson study: A handbook of teacher-led instructional change. Philadelphia, PA: Research for Better Schools.

Lewis, C. C., \& Hurd, J. (2011). Lesson study step by step. Portsmouth, NH: Heinemann.

Stigler, J. W., \& Hiebert, J. (1999). The teaching gap: Best ideas from the world's teachers for improving in the classroom. New York: The Free Press.

Uhrmacher, P. B., Conrad, B. M., \& Moroye, C. M. (2013). Finding the balance between process and product through perceptual lesson planning (pp. 1-27). New York: Teachers College Record. 